\title{
Correction to: Kolaviron via anti-inflammatory and redox regulatory mechanisms abates multi-walled carbon nanotubes-induced neurobehavioral deficits in rats
}

\author{
Isaac A. Adedara ${ }^{1}$ - Ifeoluwa O. Awogbindin ${ }^{1}$. Olatunde Owoeye ${ }^{2} \cdot$ Ikenna C. Maduako $^{1}$ - Akinola O. Ajeleti ${ }^{3}$. \\ Solomon E. Owumi ${ }^{4}$ - Anita K. Patlolla ${ }^{5}$. Ebenezer O. Farombi ${ }^{1}$
}

Published online: 27 January 2020

(C) Springer-Verlag GmbH Germany, part of Springer Nature 2020

\section{Correction to: Psychopharmacology.}

https://doi.org/10.1007/s00213-019-05432-8

After publication of this paper, the authors discovered that the name of the first author, Isaac Adegboyega Adedara, was missing in the proof. Dr. Adedara's intellectual contributions to the present article include conception and design of the study, manuscript writing and approval of the final version of the manuscript. Indeed, he submitted and revised the manuscript.

The original article has been corrected.

Publisher's note Springer Nature remains neutral with regard to jurisdictional claims in published maps and institutional affiliations.

The online version of the original article can be found at https://doi.org/ 10.1007/s00213-019-05432-8

Ebenezer O. Farombi

olatunde_farombi@yahoo.com

1 Drug Metabolism and Toxicology Research Laboratories,

Department of Biochemistry, College of Medicine, University of

Ibadan, Ibadan, Nigeria

2 Department of Anatomy, College of Medicine, University of Ibadan, Ibadan, Nigeria

3 Department of Anatomy, College of Medicine, Bowen University, Iwo, Nigeria

4 Cancer Research and Molecular Biology Laboratory, Department of Biochemistry, College of Medicine, University of Ibadan, Ibadan, Nigeria

5 College of Science Engineering and Technology, NIH-RCMI Center for Environmental Health, Jackson State University, Jackson, MS, USA 